\title{
Dopamine in socioecological and evolutionary perspectives: implications for psychiatric disorders
}

\author{
Yoshie Yamaguchi ${ }^{1}$, Young-A Lee $^{2}$ and Yukiori Goto ${ }^{1 *}$ \\ 'Section of Cognition and Learning, Department of Cognitive Science, Primate Research Institute, Kyoto University, Inuyama, \\ Japan, ${ }^{2}$ Department of Food Science and Nutrition, Catholic University of Daegu, Gyeongsan-Si, Korea
}

\section{OPEN ACCESS}

Edited by:

J. Michael Williams,

Drexel University, USA

Reviewed by:

Gregg Stanwood,

Florida State University, USA

Mehdi Khamassi,

Centre National de la Recherche

Scientifique/Université Pierre et Marie

Curie, France

*Correspondence:

Yukiori Goto,

Section of Cognition and Learning, Department of Cognitive Science,

Primate Research Institute, Kyoto

University, 41-2 Kanrin, Inuyama Aichi

484-8506, Japan

goto.yukiori.5c@kyoto-u.ac.jp

Specialty section:

This article was submitted to

Evolutionary Psychology and

Neuroscience,

a section of the journal

Frontiers in Neuroscience

Received: 15 April 2015

Accepted: 01 June 2015

Published: 16 June 2015

Citation:

Yamaguchi Y, Lee YA and Goto Y (2015) Dopamine in socioecological and evolutionary perspectives: implications for psychiatric disorders.

Front. Neurosci. 9:219

doi: 10.3389/fnins.2015.00219
Dopamine (DA) transmission in brain areas such as the prefrontal cortex (PFC) and nucleus accumbens (NAcc) plays important roles in cognitive and affective function. As such, DA deficits have been implicated in a number of psychiatric disorders such as schizophrenia and attention deficit/hyperactivity disorder (ADHD). Accumulating evidence suggests that DA is also involved in social behavior of animals and humans. Although most animals organize and live in social groups, how the DA system functions in such social groups of animals, and its dysfunction causes compromises in the groups has remained less understood. Here we propose that alterations of DA signaling and associated genetic variants and behavioral phenotypes, which have been normally considered as "deficits" in investigation at an individual level, may not necessarily yield disadvantages, but even work advantageously, depending on social contexts in groups. This hypothesis could provide a novel insight into our understanding of the biological mechanisms of psychiatric disorders, and a potential explanation that disadvantageous phenotypes associated with DA deficits in psychiatric disorders have remained in humans through evolution.

Keywords: primates, social hierarchy, social interaction, evolution, dopamine, psychiatric disorder, genetic variants

\section{Introduction}

Dopamine (DA) plays important roles in various aspects of brain function (Grace et al., 1998; Robbins, 2000) and its deficits have been implicated in a number of psychiatric disorders such as schizophrenia (Seeman, 1987; Howes and Kapur, 2009) and attention deficit/hyperactivity disorder (ADHD) (Arnsten, 2006).

In rodents and higher mammals including humans, DA neurons are located in the midbrain nuclei, the ventral tegmental area (VTA), and substantia nigra pars compacta (SNc) (Grace et al., 1998). DA neurons in the SNc projects into the dorsal striatum, consisting of the nigrostriatal pathway, whereas those in the VTA projects into the prefrontal cortex (PFC) as well as the nucleus accumbens (NAcc) and limbic structures, consisting of the mesocortical and mesolimbic pathways, respectively (Grace et al., 1998). In particular, the mesocortical and mesolimbic DA pathways play crucial roles in mediating cognitive and affective functions (Grace et al., 1998; Robbins, 2000).

DA appears to be an evolutionarily old neurotransmitter system. Use of DA molecules in neurotransmission can be found in primitive organisms such as C. elegans (Welsh, 1972). Moreover, genes, structures, and function of DA receptors with D1 and D2 subtypes are relatively conserved across invertebrates and vertebrates (Cardinaud et al., 1998; Mustard et al., 2005). Thus, original 
primary function of DA could have started with primitive ones such as motor control and reward reinforcement learning (Svensson et al., 2003; Schultz, 2013). One of the evolutionary pressures that have made the DA system utilized in higher brain functions may be associated with social environments. Humans and animals organize and live in social groups. Increasing social complexities could have driven evolution of more sophisticated brain functions (Dunbar, 2009), through which DA has consequently been utilized into the complex brain systems. Such evolutionary processes would also result in emergence of psychiatric disorders associated with DA alterations at the same time.

This article aims to provide some insights about DA function in socioecological contexts and the biological mechanisms of psychiatric disorders associated with DA dysfunction from an evolutionary perspective. In particular, DA function has been extensively investigated and understood at an individual level. On the other hand, how the DA system works in animals and humans living in natural social groups has remained less understood. We argue that DA alterations, which are also associated with psychiatric disorders and thereby normally considered as "deficits" in investigation at an individual level, may not necessarily yield disadvantages, but even work advantageously, depending on social contexts.

\section{Roles of DA in Cognitive and Affective Function}

DA signaling is involved various cognitive and affective functions, which depend on brain areas where DA neurons innervate. The mesocortical and mesolimbic DA projections in the PFC and ventral striatum (including the NAcc), respectively, are involved in cognitive functions such as working memory (Sawaguchi and Goldman-Rakic, 1991; Bushnell and Levin, 1993; Zahrt et al., 1997; Muller et al., 1998; Kahkonen et al., 2001; Mehta et al., 2004; Von Huben et al., 2006), behavioral flexibility (Floresco et al., 2006; Coppens et al., 2010; Klanker et al., 2013), attention regulation (Chudasama and Robbins, 2004; Von Huben et al., 2006; Pezze et al., 2007; Agnoli et al., 2013), and decision making (Kurniawan et al., 2011; Humphries et al., 2012; Guitart-Masip et al., 2014). The mesolimbic DA pathway in limbic structures such as the amygdala has also been shown to contribute to affective function such as fear conditioning (Pezze and Feldon, 2004). One such cognitive functions strongly associated with mesocortical DA signaling in the PFC is working memory. Alterations of working memory function, which are similar, if not identical, patterns, caused by pharmacological modulations of DA D1 and D2 receptors have been reported across different vertebrates from rodents (Bushnell and Levin, 1993; Zahrt et al., 1997), non-human primates (Sawaguchi and Goldman-Rakic, 1991; Von Huben et al., 2006), to humans (Muller et al., 1998; Kahkonen et al., 2001; Mehta et al., 2004). This suggests that an evolutionary origin of DA system utilization on cognitive functions is quite old, and have been conserved for a long time in various species.
Genetic variants that regulate DA transmission have been shown to impact on cognitive functions. One such example is the Valine158Methionine (Val158Met) single nucleotide polymorphism (SNP: rs4680) on the gene coding catechol-omethyl transferase (COMT) (Egan et al., 2001). COMT is an enzyme that degrades DA, such that COMT efficiency determines DA concentrations in brain areas such as the PFC where DA is released. COMT activity in Met-allele carriers is lower, and thereby DA availability is higher, than that in Val-allele carriers. Consequently, Met-allele carriers have been shown to exhibit better cognitive performance in working memory (Goldberg et al., 2003) and behavioral flexibility (Egan et al., 2001), although recent meta-analyses have reported that the effects are quite weak (Barnett et al., 2007, 2008). In contract, the Val-allele has been suggested as a risk factor for a psychiatric disorder such as schizophrenia (Glatt et al., 2003a). Percentages of Met-allele carriers significantly varies among ethnic groups. In Caucasians, percentages of the $\mathrm{Val} / \mathrm{Val}$ and Met/Met genotypes are approximately $20-25 \%$ each, respectively. In contrast, a percentage of the Met/Met genotype is lower than 5\%, and a percentage of the $\mathrm{Val} / \mathrm{Val}$ genotype reaches even higher than $60 \%$ in Asians (Baclig et al., 2012). Accordingly, it appears that the $\mathrm{Val} / \mathrm{Val}$ genotype, which is disadvantageous in terms of cognitive functions, have been paradoxically selected in Asians people. This increased prevalence of Val-allele carriers in Asians suggests that these people had been exposed to an environment where a behavioral trait associated with lower PFC DA may specifically be favorable on reproductive success.

\section{DA Deficits in Psychiatric Disorders}

In accordance with important roles of DA in various cognitive and affective processes, deficits in the DA system have been implicated in a number of psychiatric disorders. For instance, schizophrenia patients exhibit cognitive dysfunction such as deficits in working memory (Lee and Park, 2005), behavioral flexibility (Goldman et al., 1991), selective attention (Barch and Carter, 1998), and recall of long-term memory (Aleman et al., 1999; Reichenberg and Harvey, 2007), which have been shown to depend on DA signaling. Studies using positron emission tomography (PET) have revealed that PFC D1 receptor availability, which indicates either receptor expression, binding of DA molecules to the receptor, or DA release itself, is altered in schizophrenia patients, although the findings are quite inconsistent, with a mixture of increase (Abi-Dargham et al., 2012; Poels et al., 2013), decrease (Okubo et al., 1997; Kahkonen et al., 2001), or no change (Karlsson et al., 2002) of D1 receptor availability. In contrast, relatively consistent findings have been reported for alterations in the mechanisms of presynaptic DA synthesis in schizophrenia (Howes and Kapur, 2009). Antipsychotic drugs for treatments of schizophrenia essentially have a DA D2 receptor antagonism (Seeman, 1987). Although postmortem and human imaging studies have hitherto been unable to find a significant alteration of D2 receptor expression in the striatum of schizophrenic brains compared to that of normal subjects (Howes and Kapur, 2009), a recent genome wide association study has identified more than 100 genetic 
variants associated with schizophrenia, which includes one on the DA D2 receptor gene (DRD2) (Schizophrenia Working Group of the Psychiatric Genomics, 2014). Genetic variants on other DA pathway genes associated with schizophrenia also include those encoding COMT (Shifman et al., 2002), DA D1 receptor (DRD1) (Allen et al., 2008), and monoamine oxidase A (MAOA) (Jonsson et al., 2003), although some of these findings are often controversial (Glatt et al., 2003a,b; Munafo et al., 2005).

Another example of a psychiatric disorder that involves DA deficits is ADHD, as suggested by observations that therapeutic treatments of ADHD are achieved by DA agonists such as amphetamine (Arnsten, 2006). Human imaging studies have reported alterations of DA transporter (DAT) expression in the striatum of ADHD individuals, although these studies are highly controversial, reporting a mixture of increase, decrease, or no change of expression (Fusar-Poli et al., 2012). Genetic analyses suggest an association of the DA D4 receptor gene (DRD4) exon III 7-repeat allele with an increased risk of ADHD (Lahoste et al., 1996), although a more recent meta-analysis has reported that this association is much weaker than it was previously thought (Gonon et al., 2012). An association of an increased risk of ADHD has also been suggested with 148 bp microsatellite located $18.5 \mathrm{~kb}$ to the $5^{\prime}$ end of DA D5 receptor gene (DRD5) (Li et al., 2006).

Collectively, involvements of DA deficits in some psychiatric disorders are convincing, although it has still been unclear exactly how the DA system is altered in these disorders, despite of tremendous efforts.

\section{Roles of DA in Social Function}

Although the roles of DA in cognitive and affective functions have been extensively investigated, its roles in social function have been less clear. However, accumulating evidence suggests that DA is one of the key neurotransmitter systems that regulate social activity in animals and humans.

Social function in which DA signaling has been implicated can be expressed as variable forms from an individual level of behavior such as pair bonding (Aragona et al., 2006), parent-offspring attachment (Gammie et al., 2008), affiliative relationship (Cervenka et al., 2010), aggression (Couppis et al., 2008), play (Achterberg et al., 2014), social recognition and memory (Millan et al., 2007), and vocal communication (Leblois et al., 2010; Willuhn et al., 2014), and prosocial behavior (Saez et al., 2015), to a social structural level such as social network (Fowler et al., 2011) and social hierarchy (Nader et al., 2012).

Social behavior at individual level has been mostly investigated in rodents. For instances, strain difference of aggressive behavior in mice and its association with D1 and D2 receptor expression has been shown, with lower NAcc D1 receptor expression and higher aggression in an inbred strain of $B A L B / c$ mice compared to another inbred strain of $\mathrm{A} / \mathrm{J}$ mice that exhibit higher NAcc D1 receptor expression and lower aggression, and vice versa in D2 receptor (Couppis et al., 2008). A recent study using optogenetic manipulation of the DA system has also unveiled that ventral tegmental area (VTA)-NAcc DA transmission and activation of D1 receptor promotes social interaction with other mice (Gunaydin et al., 2014). Collectively, these studies suggest D1 receptor signaling is particularly important in the regulation of social interaction with mates. However, it is also interesting to note that this appears to be opposite in formation of pair bonding in monogamous prairie voles in which NAcc D1 receptor has been shown to prevent, whereas $\mathrm{D} 2$ receptor facilitates formation (Aragona et al., 2006), suggesting that involvements of DA transmission in social function could differ depending on which aspects of social behavior it mediates.

\section{Roles of DA in Social Hierarchy}

DA is utilized in non-vertebrates such as ants. Recent studies have shown that DA plays an important role in social hierarchy of ants, with DA concentration significantly higher in socially dominants than subordinates (Penick et al., 2014; Okada et al., 2015). A similar observation has also been reported in a bird such as ring-necked phesants, with higher social rank males exhibiting higher striatal DA concentration (Mcintyre and Chew, 1983). In contrast, in coturnix quails, this appears to be the opposite, with higher social rank subjects determined by pecking order exhibiting lower DA concentration (Holladay and Edens, 1987). However, the mechanisms creating such difference between quails and other species are unclear.

The roles of DA signaling in social hierarchy has also been suggested in higher mammals such as rodents, non-human primates, and humans. In rodents, the roles of DA on social hierarchy has been examined in a group consisting of DA transporter (DAT) knockout mice (Rodriguiz et al., 2004). Although a group of DAT knockout mice still organizes social hierarchy as does a group of normal mice, the social hierarchy in the group of DAT knockout mice was found more unstable with frequent changes of ranking over time than that of normal mice, suggesting that appropriate DA signaling is required for organizing and maintaining social hierarchy. In relation to this finding, associations of two genetic variants on the $5^{\prime}$ untrascribed region (UTR) of the DAT gene with social ranks have also been reported in rhesus and cynomolgous monkeys (MillerButterworth et al., 2008).

Studies by Nader and colleagues have shown that striatal D2 receptor availability in male and female cynomolgus monkeys under single housing is not different among subjects. However, when these monkeys are housed in a social group, and once social hierarchy is established in the group, increased D2 receptor availability, indicating higher D2 receptor expression or lower DA release, has emerged in subjects with dominant status (Morgan et al., 2002; Nader et al., 2012). Consistently with the non-human primate studies, human imaging studies have also reported a correlation between striatal D2 receptor availability and social desirability, with higher D2 availability correlating with lower social affiliation and higher social dominance (Cervenka et al., 2010). Moreover, a correlation between striatal D2 receptor availability and social status, with higher D2 availability correlating higher social status, has been reported (Martinez et al., 2010).

A recent human imaging study by Plaven-Sigray and colleagues has shown that higher D1 receptor availability in the limbic striatum is associated with higher social affiliation and 
lower social dominance and aggression (Plaven-Sigray et al., 2014), suggesting that not only D2, but also D1 receptor signaling also plays important roles in social hierarchy. Moreover, it appears that D1 and D2 receptors yield opposite effects in terms of social structural organization, which is consistent with opposite roles of D1 and D2 receptor in aggressive behavior of BALB/c and A/J mice (Couppis et al., 2008). One question brought up by this observation is, then, whether a high (or low) D1 receptor expression may be compensated by a high (or low) D2 receptor expression. If this is the case, social behavior of high D1/high D2 animals could be equivalent with that of low D1/low D2 animals. There has been no study investigating interactive effects of D1 and D2 receptors on regulation of social behavior. However, in the study comparing $\mathrm{D} 1$ and $\mathrm{D} 2$ receptor expression in $\mathrm{BALB} / \mathrm{c}$ and $\mathrm{A} / \mathrm{J}$ mice (Couppis et al., 2008), an inverse relationship between D1 and D2 receptor expression has been observed, suggesting that there may be a mechanism that prevents the counteractive effect of D1 and D2 receptors with balancing expression of these DA receptors.

Although a line of evidence suggests that serotonin (5HT) plays significant roles in social function of non-human primates (Heinze et al., 1980; Raleigh et al., 1991; Kaplan et al., 2002; Riddick et al., 2009; Embree et al., 2013; Shively et al., 2014), only a few studies have yet examined the roles of DA for regulation of social behavior in non-human primates that are housed in social groups. These studies have shown that administration of the psychostimulant, amphetamine attenuates social interaction in Java and vervet monkeys, which is reversed by a D1 receptor antagonist (Ellenbroek et al., 1989; Melega et al., 2008). In addition, administration of the D2 receptor antagonist, haloperidol also decreases social interaction in rhesus monkeys (Palit et al., 1997). Based on these observations, social interactions in non-human primates that are housed in social groups appear to be promoted and attenuated by D2 and D1 receptor stimulation, respectively, which is opposite to the findings in rodents and humans. Therefore, further investigation clarifying the mechanisms that underlie this inter-species difference is awaited.

\section{DA Pathway Genetic Variants in Social Function}

In human studies, genetic variants on DA pathway genes have been reported to affect individual social behavior and social relationships in a group. The TaqI A (A1) allele (rs1800497) which is one of the polymorphisms associated with DA D2 receptor function, although its location is not exactly within the DRD2 gene, and the adjunct gene encoding that encodes ankyrin repeat and kinase domain containing 1 (ANKK1) gene. Large social network studies have shown a positive correlation between the DRD2/ANKK1 TaqI A genotypes and friendships in the network, such that individuals with the same genotypes tend to create friendships (i.e., homophily) (Fowler et al., 2011; Boardman et al., 2012). However, a similar social network study in rhesus macaques did not find an association with DA pathway gene, but with the interactive effects of 5HT transporter-liked polymorphism region (5HTTLPR) and tryptophan hydroxylase 2 (TPH2) gene variants (Brent et al., 2013), suggesting that social network organizations in humans and non-human primates may be governed by distinct, species-specific molecules.

Both heterozygous and homozygous DRD2/ANKK1 A1-allele carriers have been reported to exhibit lower striatal D2 receptor availability than non-carriers (Thompson et al., 1997; Ritchie and Noble, 2003) [but there are also studies reporting no such difference, for instance (Laruelle et al., 1998)]. In addition, meta-analyses for studies that have investigated associations between the A1-allele and psychiatric disorders have confirmed significantly higher risks of mood disorders (Zou et al., 2012) and drug addiction such as alcoholism (Munafo et al., 2007) and smoking (Munafo et al., 2009) in carriers than noncarriers. Therefore, DRD2/ANKK1 A1-allele are disadvantageous at least in the modern human society. Nevertheless, prevalence of A1-allele carriers significantly varies among ethnic groups. Although only approximately 20 and $40 \%$ of Caucasian and American Blacks, respectively, are estimated A1-allele carriers, percentages of A1-allele carriers are estimated to be more than $60-80 \%$ in Jemez- and Cheyenee-Indians, respectively (Goldman et al., 1993). Indeed, higher prevalence of substance abuse including alcoholism and nicotine dependence in American Indians than Caucasians have been shown (May, 1982; Walters et al., 2002). No reliable data is available for prevalence of major depressive disorder in this ethnic group; however, the suicide rate in American Indians is highest among other ethnic groups in USA (Olson and Wahab, 2006), which may be indirectly associated with higher prevalence of MDD in American Indians.

Associations of the DRD2 polymorphisms with increased risks of schizophrenia, but other than the A1-allele such as C957T (rs6277) (Monakhov et al., 2008), C939T (rs6275) (Allen et al., 2008), and missense Cys311Ser (rs1801028) (Glatt et al., 2003b) variants, have also been reported. Collectively, paradoxically to the suggested disadvantageous effects of the DRD2/ANKK1 A1allele and possibly other DRD2 genetic variants, these seemingly disadvantageous genotypes could be selected under specific environments. Given the roles of D2 receptor signaling in social function, such specific environments that contribute to selections of disadvantageous DRD2 genotypes may be associated with socially-relevant ones such as social hierarchy.

\section{DA Function and Dysfunction in a Socioecological Perspective}

Considering the above discussions, one question has emerged; whether DA alterations and associated behavioral phenotypes, which underlie psychiatric disorders, may be understood as "deficits," especially in social contexts? This question is particularly coined by the observations that unfavorable genotypes associated with psychiatric disorders such as Val-allele of COMT and DRD2/ANKK1 A1-allele are selected in some human ethnic groups.

A selection of a genotype that results in a seemingly disadvantageous phenotype has been implicated as early as 1958 by Fisher (1958). Since then, several studies have documented such selections of the unfavorable genetic variants. One of the famous cases is a sickle-cell trait (Allison, 1964). Allison 
found stable prevalence of the heterozygous sickle-cell gene in African people regardless of its disadvantageous phenotype such as anemia. This is, however, associated with the fact that the sickle-cell heterozygote is at advantage against malaria infection (Beutler et al., 1955). More direct empirical evidence for natural selection of genotypes and phenotypes in response to varying environmental conditions have been shown in the fruit fly, Drosophila. For instances, drosophila larvae maintained in crowded density at later stage of development exhibit higher survival rate in a subsequent adult over-population environment (Borash et al., 1998). In addition, higher-than-average incidences of copy number duplicates and deletions on toxin-response genes has been reported, which indicates positive selections of these genetic mutations (Emerson et al., 2008).

\section{Functional Outcomes Determined by Genotype x Environment Interaction}

One of the mechanisms at stake when an unfavorable genotype is selected over the favorable one may involve environmentallyassociated epigenetic regulation of gene expression at early development.

A functional length polymorphism of the MAOA-linked polymorphism region (MAOA-LPR) has been found in rhesus macaques, with the 7-repeat (7R) allele resulting in lower MAOA activity than the 5- and 6-repeat (5R/6R) alleles (Newman et al., 2005). Such difference of MAOA activity between the alleles is also reflected as behavioral difference, such that during food competitions and ordinary social interactions with others, male macaques grown in a normal condition (i.e., reared by biological mothers or cross-fostered) with the 7R-allele (low MAOA activity) are more aggressive than those with the 5R/6Ralleles (high MAOA activity). However, this is reversed in male macaques reared in a nursery room with limited access to peers. These nursery-reared macaques with the $7 \mathrm{R}$-allele exhibit lower aggression than those with the 5R/6R-alleles.

A similar observation has also been reported in rats, in which epigenetic regulation of gene expression is suggested (Weaver et al., 2004). In this study, offsprings born from low maternal care (licking) mothers exhibited high anxiety and stress response, but when these offsprings were cross-fostered with high maternal care mothers, their anxiety and stress response is reduced. On the other hand, even if offsprings were born form high maternal care mothers, they turned to exhibit high anxiety and stress response when they were reared by low maternal care mothers. This process was mediated by removal of methylation on the $\mathrm{Nr} 3 \mathrm{C} 1$ gene, resulting in increased glucocorticoid receptor expression in the hippocampus, upon maternal licking.

\section{Behavioral Alterations at Individual Level vs. Social Group Level}

A potential selection mechanism of an unfavorable genotype may not necessarily involve alterations of gene expression by environmentally-associated epigenetic processes, but such an unfavorable genotype may also simply work better under a specific environmental condition. In relation to this argument, considerations of DA function and dysfunction under natural or semi-natural (animal) social contexts and unusual (e.g., severe stressful) environments provokes some insights. Unfortunately, most previous studies have been conducted at an individual level, and their results are interpreted in "normal" (modern human) social contexts.

For instance, that consideration of brain function and dysfunction including those associated with DA signaling in animal socioecological contexts is a promising approach is illustrated by a study investigating the effects of the N-methyl$\mathrm{d}$-asparate (NMDA) antagonist phencyclidine (PCP) in socially housed capuchin monkeys (Linn et al., 1999). Acute and chronic PCP treatments have been shown to induce behavioral alterations including cognitive and sensorimotor gating deficits that resemble to schizophrenia symptoms in humans and animals (Javitt et al., 2012). Chronic PCP administration also promotes social withdrawal in rodents (Lee et al., 2005) and non-human primates (Mao et al., 2008) when it is examined at an individual level. In contrast, chronic PCP administration even facilitates affiliative social interaction without altering aggressive behavior in socially housed non-human primates (Linn et al., 1999). Such a difference of the findings suggests that socioecological backgrounds are important for understanding of the chronic PCP effects, and that behavioral phenotypes that are thought to be deficits in one condition may not necessarily be disadvantageous in another condition.

\section{DA D1 Receptor Function in a Socioecological Perspective}

Here we discuss DA D1 and D2 receptor function and dysfunction in a non-human primate hierarchical society.

There are very few, if any, studies that have investigated D1 receptor function in animals living in a socially natural environment. We have recently conducted an experiment to investigate the effects of chronic administration of the D1 antagonist in a Japanese macaque (Macaca fuscata) housed in the semi-natural social group (unpublished observation). In this study, the effects of chronic dopamine D1 antagonist administration were examined in the second ranked subject within the social group. Before drug administration, the second ranked subject did not have food access before the first ranked subject. However, after drug administration, the second ranked subject had now frequently obtained foods even before the first ranked subject accessed. Nevertheless, the subject receiving drug administration did not have increased aggressive attacks from any other subjects including the first ranked subject in the group at any experimental stages. Since the experiment was conducted in a group of monkeys, it is hard to apply conventional cognitive and sensorimotor tests in the animal to examine the effects of drug administration. However, a persistent decrease in a number of goal directed actions after drug administration was observed, suggesting that cognitive process may be disturbed by drug administration. In addition, this experiment has hitherto been conducted only in a single animal, and therefore, awaits replications in future investigation. Nevertheless, the results suggest that behavioral traits associated with low DA D1 signaling may not be interpreted as "deficits," but rather "beneficial" in the social contexts of animals such as Japanese macaques. 
This finding in Japanese macaques could be interpreted along with the recent human imaging study showing that higher D1 receptor availability, which indicates either higher receptor expression or lower DA release, in the limbic striatum is associated with higher social affiliation, as well as lower social dominance and aggression (Plaven-Sigray et al., 2014). Thus, D1 blockade may exert low affilitative as well as more dominant and aggressive behavior. These behavioral traits associated with low D1 receptor expression would yield beneficial impacts in relatively higher social ranking subjects with close power balance between them in the group. In contrast, D1 blockade in low social ranking subjects would yield adverse impacts, which may cause more frequent defeats by higher social ranking subjects.

Thus, whether low and high D1 receptor signaling could be beneficial or detrimental may be determined by social status within a group in animals such as macaques who organize and live in a hierarchical social group. Therefore, there would be an opportunity that behavioral traits associated with low D1 receptor function are selected over high D1 receptor function, depending on social contexts.

\section{DA D2 Receptor Function in a Socioecological Perspective}

A human imaging study has shown associations between limbic striatal D2 receptor availability and social affiliation and dominance that are opposite to those of D1 receptor (Cervenka et al., 2010). Thus, beneficial effects of D2 receptor function in an animal social group are also expected to be opposite of those of D1 receptor function; low D2 receptor signaling may work advantageously in lower social ranking subjects in a group with hierarchy. Given that subjects with low D2 receptor function would exhibit a tendency of low social dominance and aggression, lower social ranking subjects with low D2 receptor function would be able to avoid attacks from higher social ranking subjects more than subjects with normal or high D2 receptor function. (Figure 1A). In contrast, subjects with low D2 receptor function would be less competitive, such that behavioral phenotypes associated with low D2 function is disadvantageous for higher social ranking subjects.

In addition to the above discussion, a number of human imaging studies have shown that D2 receptor availability in the striatum (Czoty et al., 2010; Huang et al., 2010), insular cortex (Suhara et al., 2001), and midbrain (Zald et al., 2008) are negatively correlated with novelty seeking behavior. This finding is further confirmed in animal studies in which lower D2 receptor signaling is associated with higher novelty seeking (Tournier et al., 2013). Novelty seeking could be both advantageous and disadvantageous. Novelty seeking may increase risks of lifethreatening dangers in one hand, but it may also lead to new findings. Using computational model approach, Humphries and colleagues have also proposed that cortico-basal ganglia DA signaling plays significant role in this "exploration-exploitation" trade-off (Humphries et al., 2012). In a hierarchical social group, higher ranking subjects have priorities for resource access. Thus in the condition that a social group expands too large, and a number of subjects within the group exceeds more than a resource can afford, lower social ranking subjects are unable to

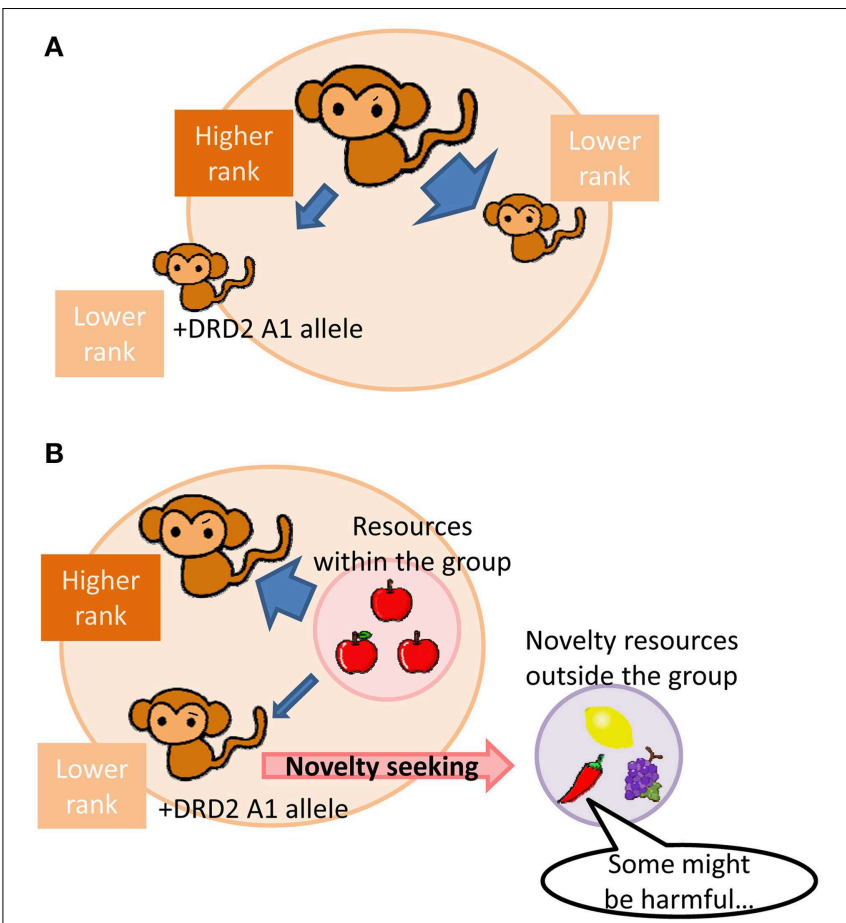

FIGURE 1 | Schematic diagrams illustrating advantageous effects of a DRD2/ANKK1 A1-allele carrier at low social status in a hierarchical group. (A) Low social dominant and aggressive traits associated with DRD2/ANKK1 A1-allele in a lower social status subject may tend to have fewer attacks (stress) from a higher social status subject than that a non-allele carrier in a group. (B) A high novelty-seeking trait with the DRD2/ANKK1 A1-allele in a lower social status subject may seek a resource from outside of a group when a number of subjects within the group exceeds a maximum allowance of a resource within the group, which may in turn eventually split the group into smaller ones.

secure the resource. A novelty seeking with low D2 receptor function would come into the advantage that aids lower social ranking subjects in the group to seek a resource from outside of the group (Figure 1B). In agreement with this idea, higher novelty seeking tendency was observed in subordinates in a cynomolgus monkey social group (Riddick et al., 2009).

Such resource seeking from outside of the belonging social group may eventually result in a split of the group. In this regards, although highly speculative, it is interesting to note that the evolutionary hypothesis of schizophrenia proposed by Stevens and Price (Stevens and Price, 2000) explains that schizophrenic traits are often observed in charismatic leaders, such that when the group gets too large, a personnel with schizophrenic traits may lead and split the group. Thus, investigation of D2 receptor function in social hierarchy and novelty seeking may eventually be able to provide a biological basis on this hypothesis.

\section{Selection Mechanisms Underlying Disadvantageous Genotypes}

Based on the above discussion, we propose two potential mechanisms of selection of a genotype that could work 
advantageously in a specific adverse environment, but otherwise disadvantageous in a normal environment.

One mechanism may involve a functional alteration of a specific genotype by interacting with an environment in early development. In this mechanism, a behavioral phenotype is reversed between specific alleles, depending on an environment that these allele carriers are exposed to early (i.e., pre- and neonatal) brain developmental periods (Figure 2A). Consequently, the allele that normally results in a disadvantageous phenotype could be favorably selected over the other allele. Such an example is illustrated in the study by Newman and colleagues that have investigated MAOA-LPR 7R-allele in non-human primates (Newman et al., 2005). Thus, macaques with low MAOA activity allele are more aggressive and competitive for food access than those with high activity allele when they are reared under normal maternal care. However, this is reversed when monkeys are reared under no or little maternal care.

The other mechanism may involve selection of a genotype under unique (and often, but not necessarily, adverse) environmental and social conditions (Figure 2B). Thus, a behavioral phenotype associated with a specific genotype may yield a disadvantage in a normal environment, but work advantageously in an unusual environment. DRD2/ANKK1 A1-allele and COMT Val-allele may be such cases.

\section{Psychiatric Disorders Associated with DA Deficits from an Evolutionary Perspective}

A recent epidemiological study has reported that fecundity rates in psychiatric patients are decreased compared to normal subjects (Power et al., 2013), which evidences that psychiatric conditions are clearly disadvantageous behavioral phenotypes in the modern human society. Nevertheless, prevalence of psychiatric disorders have been maintained constant, or in some disorders, increased more recently even after discounting diagnostic criteria changes in the diagnostic manuals (Torrey, 1987; King and Bearman, 2009; Visser et al., 2010).

Accumulating evidence suggests de novo mutations of the genes are a significant mechanism that causes psychiatric disorders such as schizophrenia and autism spectrum disorder, and could account for constant prevalence of these disorders (Sullivan et al., 2012; Veltman and Brunner, 2012). In contrast, it has been estimated that such de novo mutations could account for only a small percentage of cases, and a majority of cases is still caused by additive effects of multiple common genetic variants with each gene variant contributing a small effect (Mcclellan et al., 2007; Awadalla et al., 2010). Therefore, constant prevalence of psychiatric disorders cannot be fully explained by the mechanism of de novo mutations. Moreover, even if such de novo mutations were the major mechanism that causes psychiatric disorders, it is still unclear why specific neural systems such as the DA system have been chosen to be altered in these psychiatric disorders.

Indeed, behavioral traits associated with psychiatric disorders are thought to have emerged at some points of evolution, and have been inherited into humans. A number of hypotheses have been proposed, arguing that some aspects of psychiatric symptoms associated with DA alterations operate advantageously in specific environmental contexts. For instance, ADHD is one of such psychiatric disorders in which DA deficits have been implicated, but advantageous aspects of its symptoms are relatively clear. The core symptoms of ADHD consist of hyperactivity, impulsivity, and inattention, all of which involve DA signaling. Administration of DA agonists such as psychostimulants causes hyperlocomotion in rodents (Vanderschuren and Kalivas, 2000). Impulsivity can be examined using a behavioral task such as a delay discounting task in rodents in which a choice of either a large reward after a delay or a small reward without a delay is weighted. Using this test,

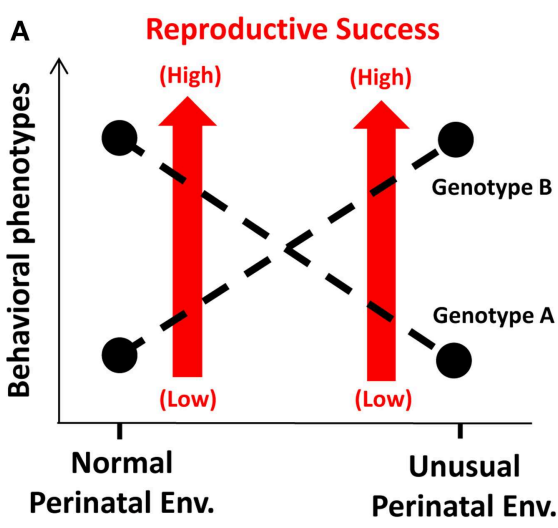

A advantageous in normal condition. Change of environment reverts behavioral phenotypes.

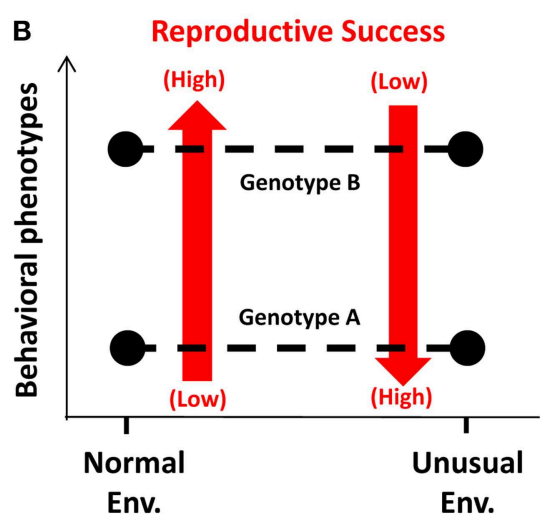

A disadvantageous in normal condition. Change of environment maintains behavioral phenotypes.
FIGURE 2 | Schematic diagrams illustrating the mechanisms underlying selection of disadvantageous genotypes over advantageous ones under specific conditions. (A) The mechanism that involves functional alterations of a genotype through epigenetic modulation of gene expression by interacting with a perinatal environment. (B) The mechanism that a postnatal environment affects reproductive success of a subject in which a disadvantageous behavioral phenotype in a normal environment may work advantageously in an unusual, adverse environment. 
administration of a D1 receptor antagonist has been shown to shift a choice for a more impulsive, immediate access to obtain a small reward over a delayed large reward (Koffarnus et al., 2011). An ability to focus and sustain attention to a particular target has also been shown to be impaired by administration of D1 and D2 antagonists in rodents (Pezze et al., 2007; Agnoli et al., 2013), non-human primates (Von Huben et al., 2006), and humans (Muller et al., 1998; Kahkonen et al., 2001; Mehta et al., 2004). These ADHD symptoms are inappropriate in the modern human social system. In contrast, they could yield great advantages for animals living in a wild environment and for humans (or ancestries of humans) living in a hunter-gatherer society (Jensen et al., 1997). Thus, exploration of a larger field and more frequent scanning of the field with a short span of attention as consequence of hyperactivity and impaired sustained attention, respectively, enable faster detection of a predator. In addition, impulsivity enables a quick decision to escape from a predator. These behavioral phenotypes could therefore facilitate survival and reproduction in a wild life environment.

Psychiatric disorders in which DA deficits are implicated exhibit cognitive dysfunction. Such cognitive deficits are often similar, if not identical, across different disorders. For instance, impulsivity is a behavioral trait that is observed not only in ADHD, but also in other psychiatric disorders such as schizophrenia (Ouzier, 2013), obsessive compulsive disorder (Fontenelle et al., 2011), and drug addiction (Fontenelle et al., 2011; Grant and Chamberlain, 2014). Similarly, an impairment of sustained attention is also not a unique feature of $\mathrm{ADHD}$, but also observed in other psychiatric disorders in which DA deficits are implicated (Coull, 1998; Chen and Faraone, 2000;

\section{References}

Abi-Dargham, A., Xu, X., Thompson, J. L., Gil, R., Kegeles, L. S., Urban, N., et al. (2012). Increased prefrontal cortical D(1) receptors in drug naive patients with schizophrenia: a PET study with $[(1)(1) \mathrm{C}] \mathrm{NNC112}$. J. Psychopharmacol. 26, 794-805. doi: 10.1177/0269881111409265

Achterberg, E. J., Trezza, V., Siviy, S. M., Schrama, L., Schoffelmeer, A. N., and Vanderschuren, L. J. (2014). Amphetamine and cocaine suppress social play behavior in rats through distinct mechanisms. Psychopharmacology (Berl) 231, 1503-1515. doi: 10.1007/s00213-013-3272-9

Agnoli, L., Mainolfi, P., Invernizzi, R. W., and Carli, M. (2013). Dopamine D1-like and D2-like receptors in the dorsal striatum control different aspects of attentional performance in the five-choice serial reaction time task under a condition of increased activity of corticostriatal inputs. Neuropsychopharmacology 38, 701-714. doi: 10.1038/npp.20 12.236

Aleman, A., Hijman, R., De Haan, E. H., and Kahn, R. S. (1999). Memory impairment in schizophrenia: a meta-analysis. Am. J. Psychiatry 156, 1358-1366.

Allen, N. C., Bagade, S., Mcqueen, M. B., Ioannidis, J. P., Kavvoura, F. K., Khoury, M. J., et al. (2008). Systematic meta-analyses and field synopsis of genetic association studies in schizophrenia: the SzGene database. Nat. Genet. 40, 827-834. doi: 10.1038/ng.171

Allison, A. C. (1964). Polymorphism and natural selection in human populations. Cold Spring Harb. Symp. Quant. Biol. 29, 137-149. doi: 10.1101/SQB.1964.029.01.018
Bellgrove and Mattingley, 2008). Thus, some cognitive deficits associated with altered DA transmission may represent general and fundamental aspects of psychiatric conditions, and may have evolutionary overlapping roots in terms of adaptations to specific environmental conditions.

\section{Conclusions}

In this article, we have presented the concept, along with supporting literatures, that alterations of the DA system associated with psychiatric disorders such as schizophrenia may not necessarily work disadvantageously in specific socioecological contexts of animals such as non-human primates. This may provide biological explanations why genetic variants on several psychiatric disorder-associated genes such as DRD2 and COMT have been selected or maintained through evolution in humans. Reconsideration of psychiatric disorders with DA deficits from an evolutionary perspective would yield novel insights into our understanding, and open a new venue on research unveiling the biological mechanisms, and thereby prevention and therapeutic treatments, of psychiatric disorders.

\section{Acknowledgments}

The authors were supported by JSPS Research Fellowship for Young Scientists \#15J01210 (YY), Basic Science Research Program through the National Research Foundation of Korea \#NRF-2014R1A1A3052796 (YAL), JSPS Grant-in-Aid for Challenging Exploratory Research \#26640044, research grants from the Institute of Seizon \& Life Sciences, Kyoto University, Chubei Ito Foundation, Ichiro Kanahara Foundation (YG).

Aragona, B. J., Liu, Y., Yu, Y. J., Curtis, J. T., Detwiler, J. M., Insel, T. R., et al. (2006). Nucleus accumbens dopamine differentially mediates the formation and maintenance of monogamous pair bonds. Nat. Neurosci. 9, 133-139. doi: $10.1038 / \mathrm{nn} 1613$

Arnsten, A. F. (2006). Stimulants: therapeutic actions in ADHD. Neuropsychopharmacology 31, 2376-2383. doi: 10.1038/sj.npp.1301164

Awadalla, P., Gauthier, J., Myers, R. A., Casals, F., Hamdan, F. F., Griffing, A. R., et al. (2010). Direct measure of the de novo mutation rate in autism and schizophrenia cohorts. Am. J. Hum. Genet. 87, 316-324. doi: 10.1016/j.ajhg.2010.07.019

Baclig, M. O., Predicala, R. Z., Mapua, C. A., Lozano-Kuhne, J. P., Daroy, M. L., Natividad, F. F., et al. (2012). Allelic and genotype frequencies of catechol-O-methyltransferase (Val158Met) and CYP2D6*10 (Pro34Ser) single nucleotide polymorphisms in the Philippines. Int. J. Mol. Epidemiol. Genet. 3, 115-121.

Barch, D. M., and Carter, C. S. (1998). Selective attention in schizophrenia: relationship to verbal working memory. Schizophr. Res. 33, 53-61. doi: 10.1016/S0920-9964(98)00064-4

Barnett, J. H., Jones, P. B., Robbins, T. W., and Muller, U. (2007). Effects of the catechol-O-methyltransferase Val158Met polymorphism on executive function: a meta-analysis of the Wisconsin Card Sort Test in schizophrenia and healthy controls. Mol. Psychiatry 12, 502-509. doi: 10.1038/sj.mp.4001973

Barnett, J. H., Scoriels, L., and Munafo, M. R. (2008). Meta-analysis of the cognitive effects of the catechol-O-methyltransferase gene Val158/108Met polymorphism. Biol. Psychiatry 64, 137-144. doi: 10.1016/j.biopsych.2008.01.005 
Bellgrove, M. A., and Mattingley, J. B. (2008). Molecular genetics of attention. Ann. N.Y. Acad. Sci. 1129, 200-212. doi: 10.1196/annals.1417.013

Beutler, E., Dern, R. J., and Flanagan, C. L. (1955). Effect of sickle-cell trait on resistance to malaria. Br. Med. J. 1, 1189-1191. doi: 10.1136/bmj.1.492 3.1189

Boardman, J. D., Domingue, B. W., and Fletcher, J. M. (2012). How social and genetic factors predict friendship networks. Proc. Natl. Acad. Sci. U.S.A. 109, 17377-17381. doi: 10.1073/pnas.1208975109

Borash, D. J., Gibbs, A. G., Joshi, A., and Mueller, L. D. (1998). A genetic polymorphism maintained by natural selection in a temporally varying environment. Am. Nat. 151, 148-156. doi: 10.1086/286108

Brent, L. J., Heilbronner, S. R., Horvath, J. E., Gonzalez-Martinez, J., RuizLambides, A., Robinson, A. G., et al. (2013). Genetic origins of social networks in rhesus macaques. Sci. Rep. 3:1042. doi: 10.1038/srep01042

Bushnell, P. J., and Levin, E. D. (1993). Effects of dopaminergic drugs on working and reference memory in rats. Pharmacol. Biochem. Behav. 45, 765-776. doi: 10.1016/0091-3057(93)90119-E

Cardinaud, B., Gibert, J. M., Sugamori, K. S., Vincent, J. D., Niznik, H. B., and Vernier, P. (1998). Comparative aspects of dopaminergic neurotransmission in vertebrates. Ann. N.Y. Acad. Sci. 839, 47-52. doi: 10.1111/j.17496632.1998.tb10731.x

Cervenka, S., Gustavsson, J. P., Halldin, C., and Farde, L. (2010). Association between striatal and extrastriatal dopamine D2-receptor binding and social desirability. Neuroimage 50, 323-328. doi: 10.1016/j.neuroimage.2009.12.006

Chen, W. J., and Faraone, S. V. (2000). Sustained attention deficits as markers of genetic susceptibility to schizophrenia. Am. J. Med. Genet. 97, 52-57. doi: 10.1002/(SICI)1096-8628(200021)97:1<52::AID-AJMG7>3.0.CO;2-6

Chudasama, Y., and Robbins, T. W. (2004). Psychopharmacological approaches to modulating attention in the five-choice serial reaction time task: implications for schizophrenia. Psychopharmacology (Berl) 174, 86-98. doi: 10.1007/s00213004-1805-y

Coppens, C. M., De Boer, S. F., and Koolhaas, J. M. (2010). Coping styles and behavioural flexibility: towards underlying mechanisms. Philos. Trans. R. Soc. Lond. B Biol. Sci. 365, 4021-4028. doi: 10.1098/rstb.2010.0217

Coull, J. T. (1998). Neural correlates of attention and arousal: insights from electrophysiology, functional neuroimaging and psychopharmacology. Prog. Neurobiol. 55, 343-361. doi: 10.1016/S0301-0082(98)00011-2

Couppis, M. H., Kennedy, C. H., and Stanwood, G. D. (2008). Differences in aggressive behavior and in the mesocorticolimbic DA system between $\mathrm{A} / \mathrm{J}$ and BALB/cJ mice. Synapse 62, 715-724. doi: 10.1002/syn.20545

Czoty, P. W., Gage, H. D., and Nader, M. A. (2010). Differences in D2 dopamine receptor availability and reaction to novelty in socially housed male monkeys during abstinence from cocaine. Psychopharmacology (Berl) 208, 585-592. doi: 10.1007/s00213-009-1756-4

Dunbar, R. I. (2009). The social brain hypothesis and its implications for social evolution. Ann. Hum. Biol. 36, 562-572. doi: 10.1080/03014460902960289

Egan, M. F., Goldberg, T. E., Kolachana, B. S., Callicott, J. H., Mazzanti, C. M., Straub, R. E., et al. (2001). Effect of COMT Val108/158 Met genotype on frontal lobe function and risk for schizophrenia. Proc. Natl. Acad. Sci. U.S.A. 98, 6917-6922. doi: 10.1073/pnas.111134598

Ellenbroek, B. A., Willemen, A. P., and Cools, A. R. (1989). Are antagonists of dopamine D1 receptors drugs that attenuate both positive and negative symptoms of schizophrenia? A pilot study in Java monkeys. Neuropsychopharmacology 2, 191-199. doi: 10.1016/0893-133X(89)90022-5

Embree, M., Michopoulos, V., Votaw, J. R., Voll, R. J., Mun, J., Stehouwer, J. S., et al. (2013). The relation of developmental changes in brain serotonin transporter (5HTT) and 5HT1A receptor binding to emotional behavior in female rhesus monkeys: effects of social status and 5HTT genotype. Neuroscience 228, 83-100. doi: 10.1016/j.neuroscience.2012.10.016

Emerson, J. J., Cardoso-Moreira, M., Borevitz, J. O., and Long, M. (2008). Natural selection shapes genome-wide patterns of copy-number polymorphism in Drosophila melanogaster. Science 320, 1629-1631. doi: $10.1126 /$ science. 1158078

Fisher, R. A. (1958). Polymorphism and natural selection. J. Ecol. 46, 289-293. doi: $10.2307 / 2257396$

Floresco, S. B., Magyar, O., Ghods-Sharifi, S., Vexelman, C., and Tse, M. T. (2006). Multiple dopamine receptor subtypes in the medial prefrontal cortex of the rat regulate set-shifting. Neuropsychopharmacology 31, 297-309. doi: 10.1038/sj.npp. 1300825

Fontenelle, L. F., Oostermeijer, S., Harrison, B. J., Pantelis, C., and Yucel, M. (2011). Obsessive-compulsive disorder, impulse control disorders and drug addiction: common features and potential treatments. Drugs 71, 827-840. doi: 10.2165/11591790-000000000-00000

Fowler, J. H., Settle, J. E., and Christakis, N. A. (2011). Correlated genotypes in friendship networks. Proc. Natl. Acad. Sci. U.S.A. 108, 1993-1997. doi: 10.1073/pnas.1011687108

Fusar-Poli, P., Rubia, K., Rossi, G., Sartori, G., and Balottin, U. (2012). Striatal dopamine transporter alterations in ADHD: pathophysiology or adaptation to psychostimulants? A meta-analysis. Am. J. Psychiatry 169, 264-272. doi: 10.1176/appi.ajp.2011.11060940

Gammie, S. C., Edelmann, M. N., Mandel-Brehm, C., D’anna, K. L., Auger, A. P., and Stevenson, S. A. (2008). Altered dopamine signaling in naturally occurring maternal neglect. PLoS ONE 3:e1974. doi: 10.1371/journal.pone.0001974

Glatt, S. J., Faraone, S. V., and Tsuang, M. T. (2003a). Association between a functional catechol O-methyltransferase gene polymorphism and schizophrenia: meta-analysis of case-control and family-based studies. Am. J. Psychiatry 160, 469-476. doi: 10.1176/appi.ajp.160.3.469

Glatt, S. J., Faraone, S. V., and Tsuang, M. T. (2003b). Meta-analysis identifies an association between the dopamine D2 receptor gene and schizophrenia. Mol. Psychiatry 8, 911-915. doi: 10.1038/sj.mp.4001321

Goldberg, T. E., Egan, M. F., Gscheidle, T., Coppola, R., Weickert, T., Kolachana, B. S., et al. (2003). Executive subprocesses in working memory: relationship to catechol-O-methyltransferase Val158Met genotype and schizophrenia. Arch. Gen. Psychiatry 60, 889-896. doi: 10.1001/archpsyc.60.9.889

Goldman, D., Brown, G. L., Albaugh, B., Robin, R., Goodson, S., Trunzo, M., et al. (1993). DRD2 dopamine receptor genotype, linkage disequilibrium, and alcoholism in American Indians and other populations. Alcohol Clin. Exp. Res. 17, 199-204. doi: 10.1111/j.1530-0277.1993.tb00749.x

Goldman, R. S., Axelrod, B. N., Tandon, R., and Berent, S. (1991). Analysis of executive functioning in schizophrenics using the Wisconsin Card Sorting Test. J. Nerv. Ment. Dis. 179, 507-508. doi: 10.1097/00005053-199108000-00014

Gonon, F., Konsman, J. P., Cohen, D., and Boraud, T. (2012). Why most biomedical findings echoed by newspapers turn out to be false: the case of attention deficit hyperactivity disorder. PLOS ONE 7:e44275. doi: 10.1371/journal.pone.0044275

Grace, A. A., Gerfen, C. R., and Aston-Jones, G. (1998). Catecholamines in the central nervous system. Overview. Adv. Pharmacol. 42, 655-670.

Grant, J. E., and Chamberlain, S. R. (2014). Impulsive action and impulsive choice across substance and behavioral addictions: cause or consequence? Addict. Behav. 39, 1632-1639. doi: 10.1016/j.addbeh.2014.04.022

Guitart-Masip, M., Duzel, E., Dolan, R., and Dayan, P. (2014). Action versus valence in decision making. Trends Cogn. Sci. 18, 194-202. doi: 10.1016/j.tics.2014.01.003

Gunaydin, L. A., Grosenick, L., Finkelstein, J. C., Kauvar, I. V., Fenno, L. E., Adhikari, A., et al. (2014). Natural neural projection dynamics underlying social behavior. Cell 157, 1535-1551. doi: 10.1016/j.cell.2014.05.017

Heinze, W. J., Schlemmer, R. F. Jr., Williams, E. A., and Davis, J. M. (1980). The acute and chronic effect of 5-methoxytryptamine on selected members of a primate social colony. Biol. Psychiatry 15, 829-839.

Holladay, S. D., and Edens, F. W. (1987). Effect of cage density and rank in peck order on brain regional monoamines in adult male Coturnix coturnix japonica. Comp. Biochem. Physiol. A Comp. Physiol. 87, 261-265. doi: 10.1016/03009629(87)90121-6

Howes, O. D., and Kapur, S. (2009). The dopamine hypothesis of schizophrenia: version III-the final common pathway. Schizophr. Bull 35, 549-562. doi: $10.1093 / \mathrm{schbul} / \mathrm{sbp} 006$

Huang, H. Y., Lee, I. H., Chen, K. C., Yeh, T. L., Chen, P. S., Yang, Y. K., et al. (2010). Association of novelty seeking scores and striatal dopamine $D(2) / D(3)$ receptor availability of healthy volunteers: single photon emission computed tomography with (1)(2)(3)i-iodobenzamide. J. Formos Med. Assoc. 109, 736-739. doi: 10.1016/S0929-6646(10)60119-2

Humphries, M. D., Khamassi, M., and Gurney, K. (2012). Dopaminergic control of the exploration-exploitation Trade-Off via the Basal Ganglia. Front. Neurosci. 6:9. doi: 10.3389/fnins.2012.00009 
Javitt, D. C., Zukin, S. R., Heresco-Levy, U., and Umbricht, D. (2012). Has an angel shown the way? Etiological and therapeutic implications of the PCP/NMDA model of schizophrenia. Schizophr. Bull. 38, 958-966. doi: $10.1093 / \mathrm{schbul} / \mathrm{sbs} 069$

Jensen, P. S., Mrazek, D., Knapp, P. K., Steinberg, L., Pfeffer, C., Schowalter, J., et al. (1997). Evolution and revolution in child psychiatry: ADHD as a disorder of adaptation. J. Am. Acad. Child Adolesc. Psychiatry 36, 1672-1679; discussion 1679-1681. doi: 10.1097/00004583-199712000-00015

Jonsson, E. G., Norton, N., Forslund, K., Mattila-Evenden, M., Rylander, G., Asberg, M., et al. (2003). Association between a promoter variant in the monoamine oxidase A gene and schizophrenia. Schizophr. Res. 61, 31-37. doi: 10.1016/S0920-9964(02)00224-4

Kahkonen, S., Ahveninen, J., Jaaskelainen, I. P., Kaakkola, S., Naatanen, R., Huttunen, J., et al. (2001). Effects of haloperidol on selective attention: a combined whole-head MEG and high-resolution EEG study. Neuropsychopharmacology 25, 498-504. doi: 10.1016/S0893-133X(01)00255-X

Kaplan, J. R., Manuck, S. B., Fontenot, M. B., and Mann, J. J. (2002). Central nervous system monoamine correlates of social dominance in cynomolgus monkeys (Macaca fascicularis). Neuropsychopharmacology 26, 431-443. doi: 10.1016/S0893-133X(01)00344-X

Karlsson, P., Farde, L., Halldin, C., and Sedvall, G. (2002). PET study of D(1) dopamine receptor binding in neuroleptic-naive patients with schizophrenia. Am. J. Psychiatry 159, 761-767. doi: 10.1176/appi.ajp.159.5.761

King, M., and Bearman, P. (2009). Diagnostic change and the increased prevalence of autism. Int. J. Epidemiol. 38, 1224-1234. doi: 10.1093/ije/dyp261

Klanker, M., Feenstra, M., and Denys, D. (2013). Dopaminergic control of cognitive flexibility in humans and animals. Front. Neurosci. 7:201. doi: 10.3389/fnins.2013.00201

Koffarnus, M. N., Newman, A. H., Grundt, P., Rice, K. C., and Woods, J. H. (2011). Effects of selective dopaminergic compounds on a delay-discounting task. Behav. Pharmacol. 22, 300-311. doi: 10.1097/FBP.0b013e3283473bcb

Kurniawan, I. T., Guitart-Masip, M., and Dolan, R. J. (2011). Dopamine and effortbased decision making. Front. Neurosci. 5:81. doi: 10.3389/fnins.2011.00081

Lahoste, G. J., Swanson, J. M., Wigal, S. B., Glabe, C., Wigal, T., King, N., et al. (1996). Dopamine D4 receptor gene polymorphism is associated with attention deficit hyperactivity disorder. Mol. Psychiatry 1, 121-124.

Laruelle, M., Gelernter, J., and Innis, R. B. (1998). D2 receptors binding potential is not affected by Taq1 polymorphism at the D2 receptor gene. Mol. Psychiatry 3, 261-265. doi: 10.1038/sj.mp. 4000343

Leblois, A., Wendel, B. J., and Perkel, D. J. (2010). Striatal dopamine modulates basal ganglia output and regulates social context-dependent behavioral variability through D1 receptors. J. Neurosci. 30, 5730-5743. doi: 10.1523/JNEUROSCI.5974-09.2010

Lee, J., and Park, S. (2005). Working memory impairments in schizophrenia: a meta-analysis. J. Abnorm. Psychol. 114, 599-611. doi: 10.1037/0021843X.114.4.599

Lee, P. R., Brady, D. L., Shapiro, R. A., Dorsa, D. M., and Koenig, J. I. (2005). Social interaction deficits caused by chronic phencyclidine administration are reversed by oxytocin. Neuropsychopharmacology 30, 1883-1894. doi: 10.1038/s.npp.1300722

Li, D., Sham, P. C., Owen, M. J., and He, L. (2006). Meta-analysis shows significant association between dopamine system genes and attention deficit hyperactivity disorder (ADHD). Hum. Mol. Genet. 15, 2276-2284. doi: 10.1093/hmg/ddl152

Linn, G. S., O'keeffe, R. T., Schroeder, C. E., Lifshitz, K., and Javitt, D. C. (1999). Behavioral effects of chronic phencyclidine in monkeys. Neuroreport 10, 2789-2793. doi: 10.1097/00001756-199909090-00017

Mao, C. V., Hori, E., Maior, R. S., Ono, T., and Nishijo, H. (2008). A primate model of schizophrenia using chronic PCP treatment. Rev. Neurosci. 19, 83-89. doi: 10.1515/REVNEURO.2008.19.2-3.83

Martinez, D., Orlowska, D., Narendran, R., Slifstein, M., Liu, F., Kumar, D., et al. (2010). Dopamine type $2 / 3$ receptor availability in the striatum and social status in human volunteers. Biol. Psychiatry 67, 275-278. doi: 10.1016/j.biopsych.2009.07.037

May, P. A. (1982). Substance abuse and American Indians: prevalence and susceptibility. Int. J. Addict. 17, 1185-1209. doi: 10.3109/10826088209056349

Mcclellan, J. M., Susser, E., and King, M. C. (2007). Schizophrenia: a common disease caused by multiple rare alleles. Br. J. Psychiatry 190, 194-199. doi: 10.1192/bjp.bp.106.025585
Mcintyre, D. C., and Chew, G. L. (1983). Relation between social rank, submissive behavior, and brain catecholamine levels in ring-necked pheasants (Phasianus colchicus). Behav. Neurosci. 97, 595-601. doi: 10.1037/0735-7044. 97.4.595

Mehta, M. A., Manes, F. F., Magnolfi, G., Sahakian, B. J., and Robbins, T. W. (2004). Impaired set-shifting and dissociable effects on tests of spatial working memory following the dopamine D2 receptor antagonist sulpiride in human volunteers. Psychopharmacology (Berl) 176, 331-342. doi: 10.1007/s00213-004-1899-2

Melega, W. P., Jorgensen, M. J., Lacan, G., Way, B. M., Pham, J., Morton, G., et al. (2008). Long-term methamphetamine administration in the vervet monkey models aspects of a human exposure: brain neurotoxicity and behavioral profiles. Neuropsychopharmacology 33, 1441-1452. doi: 10.1038/sj.npp.1301502

Millan, M. J., Di Cara, B., Dekeyne, A., Panayi, F., De Groote, L., Sicard, D., et al. (2007). Selective blockade of dopamine $D(3)$ versus $D(2)$ receptors enhances frontocortical cholinergic transmission and social memory in rats: a parallel neurochemical and behavioural analysis. J. Neurochem. 100, 1047-1061. doi: 10.1111/j.1471-4159.2006.04262.x

Miller-Butterworth, C. M., Kaplan, J. R., Shaffer, J., Devlin, B., Manuck, S. B., and Ferrell, R. E. (2008). Sequence variation in the primate dopamine transporter gene and its relationship to social dominance. Mol. Biol. Evol. 25, 18-28. doi: 10.1093/molbev/msm219

Monakhov, M., Golimbet, V., Abramova, L., Kaleda, V., and Karpov, V. (2008). Association study of three polymorphisms in the dopamine D2 receptor gene and schizophrenia in the Russian population. Schizophr. Res. 100, 302-307. doi: 10.1016/j.schres.2008.01.007

Morgan, D., Grant, K. A., Gage, H. D., Mach, R. H., Kaplan, J. R., Prioleau, O. et al. (2002). Social dominance in monkeys: dopamine D2 receptors and cocaine self-administration. Nat. Neurosci. 5, 169-174. doi: 10.1038/nn798

Muller, U., Von Cramon, D. Y., and Pollmann, S. (1998). D1- versus D2-receptor modulation of visuospatial working memory in humans. J. Neurosci. 18, $2720-2728$.

Munafo, M. R., Bowes, L., Clark, T. G., and Flint, J. (2005). Lack of association of the COMT (Val158/108 Met) gene and schizophrenia: a meta-analysis of case-control studies. Mol. Psychiatry 10, 765-770. doi: 10.1038/sj.mp.4001664

Munafo, M. R., Matheson, I. J., and Flint, J. (2007). Association of the DRD2 gene Taq1A polymorphism and alcoholism: a meta-analysis of case-control studies and evidence of publication bias. Mol. Psychiatry 12, 454-461. doi: 10.1038/sj.mp. 4001938

Munafo, M. R., Timpson, N. J., David, S. P., Ebrahim, S., and Lawlor, D. A. (2009). Association of the DRD2 gene Taq1A polymorphism and smoking behavior: a meta-analysis and new data. Nicotine Tob. Res. 11, 64-76. doi: $10.1093 / \mathrm{ntr} / \mathrm{ntn} 012$

Mustard, J. A., Beggs, K. T., and Mercer, A. R. (2005). Molecular biology of the invertebrate dopamine receptors. Arch. Insect Biochem. Physiol. 59, 103-117. doi: $10.1002 /$ arch. 20065

Nader, M. A., Nader, S. H., Czoty, P. W., Riddick, N. V., Gage, H. D., Gould, R. W., et al. (2012). Social dominance in female monkeys: dopamine receptor function and cocaine reinforcement. Biol. Psychiatry 72, 414-421. doi: 10.1016/j.biopsych.2012.03.002

Newman, T. K., Syagailo, Y. V., Barr, C. S., Wendland, J. R., Champoux, M., Graessle, M., et al. (2005). Monoamine oxidase A gene promoter variation and rearing experience influences aggressive behavior in rhesus monkeys. Biol. Psychiatry 57, 167-172. doi: 10.1016/j.biopsych.2004.10.012

Okada, Y., Sasaki, K., Miyazaki, S., Shimoji, H., Tsuji, K., and Miura, T. (2015). Social dominance and reproductive differentiation mediated by dopaminergic signaling in a queenless ant. J. Exp. Biol. 218, 1091-1098. doi: $10.1242 /$ jeb.118414

Okubo, Y., Suhara, T., Suzuki, K., Kobayashi, K., Inoue, O., Terasaki, O., et al. (1997). Decreased prefrontal dopamine D1 receptors in schizophrenia revealed by PET. Nature 385, 634-636. doi: 10.1038/385634a0

Olson, L. M., and Wahab, S. (2006). American Indians and suicide: a neglected area of research. Trauma Violence Abuse 7, 19-33. doi: 10.1177/1524838005283005

Ouzier, M. (2013). Impulsivity in schizophrenia: a comprehensive update. Aggression Violent Behav. 18, 247-254. doi: 10.1016/j.avb.2012.11.014

Palit, G., Kumar, R., Gupta, M. B., Saxena, R. C., Patnaik, G. K., and Dhawan, B. N. (1997). Quantification of behaviour in social colonies of rhesus monkey. Indian J. Physiol. Pharmacol. 41, 219-226. 
Penick, C. A., Brent, C. S., Dolezal, K., and Liebig, J. (2014). Neurohormonal changes associated with ritualized combat and the formation of a reproductive hierarchy in the ant Harpegnathos saltator. J. Exp. Biol. 217, 1496-1503. doi: 10.1242/jeb.098301

Pezze, M. A., Dalley, J. W., and Robbins, T. W. (2007). Differential roles of dopamine D1 and D2 receptors in the nucleus accumbens in attentional performance on the five-choice serial reaction time task. Neuropsychopharmacology 32, 273-283. doi: 10.1038/sj.npp.1301073

Pezze, M. A., and Feldon, J. (2004). Mesolimbic dopaminergic pathways in fear conditioning. Prog. Neurobiol. 74, 301-320. doi: 10.1016/j.pneurobio.2004.09.004

Plaven-Sigray, P., Gustavsson, P., Farde, L., Borg, J., Stenkrona, P., Nyberg, L., et al. (2014). Dopamine D1 receptor availability is related to social behavior: a positron emission tomography study. Neuroimage 102(Pt 2), 590-595. doi: 10.1016/j.neuroimage.2014.08.018

Poels, E. M., Girgis, R. R., Thompson, J. L., Slifstein, M., and AbiDargham, A. (2013). In vivo binding of the dopamine-1 receptor PET tracers [(1)(1)C]NNC112 and [(1)(1)C]SCH23390: a comparison study in individuals with schizophrenia. Psychopharmacology (Berl) 228, 167-174. doi: 10.1007/s00213-013-3026-8

Power, R. A., Kyaga, S., Uher, R., Maccabe, J. H., Langstrom, N., Landen, M., et al. (2013). Fecundity of patients with schizophrenia, autism, bipolar disorder, depression, anorexia nervosa, or substance abuse vs their unaffected siblings. JAMA Psychiatry 70, 22-30. doi: 10.1001/jamapsychiatry.2013.268

Raleigh, M. J., Mcguire, M. T., Brammer, G. L., Pollack, D. B., and Yuwiler, A. (1991). Serotonergic mechanisms promote dominance acquisition in adult male vervet monkeys. Brain Res. 559, 181-190. doi: 10.1016/00068993(91)90001-C

Reichenberg, A., and Harvey, P. D. (2007). Neuropsychological impairments in schizophrenia: integration of performance-based and brain imaging findings. Psychol. Bull. 133, 833-858. doi: 10.1037/0033-2909. 133.5.833

Riddick, N. V., Czoty, P. W., Gage, H. D., Kaplan, J. R., Nader, S. H., Icenhower, M., et al. (2009). Behavioral and neurobiological characteristics influencing social hierarchy formation in female cynomolgus monkeys. Neuroscience 158, 1257-1265. doi: 10.1016/j.neuroscience.2008.11.016

Ritchie, T., and Noble, E. P. (2003). Association of seven polymorphisms of the D2 dopamine receptor gene with brain receptor-binding characteristics. Neurochem. Res. 28, 73-82. doi: 10.1023/A:1021648128758

Robbins, T. W. (2000). Chemical neuromodulation of frontal-executive functions in humans and other animals. Exp. Brain Res. 133, 130-138. doi: $10.1007 / \mathrm{s} 002210000407$

Rodriguiz, R. M., Chu, R., Caron, M. G., and Wetsel, W. C. (2004). Aberrant responses in social interaction of dopamine transporter knockout mice. Behav. Brain Res. 148, 185-198. doi: 10.1016/S0166-4328(03)00187-6

Saez, I., Zhu, L., Set, E., Kayser, A., and Hsu, M. (2015). Dopamine modulates egalitarian behavior in humans. Curr. Biol. 25, 912-919. doi: 10.1016/j.cub.2015.01.071

Sawaguchi, T., and Goldman-Rakic, P. S. (1991). D1 dopamine receptors in prefrontal cortex: involvement in working memory. Science 251, 947-950. doi: $10.1126 /$ science. 1825731

Schizophrenia Working Group of the Psychiatric Genomics, C. (2014). Biological insights from 108 schizophrenia-associated genetic loci. Nature 511, 421-427. doi: $10.1038 /$ nature 13595

Schultz, W. (2013). Updating dopamine reward signals. Curr. Opin. Neurobiol. 23, 229-238. doi: 10.1016/j.conb.2012.11.012

Seeman, P. (1987). Dopamine receptors and the dopamine hypothesis of schizophrenia. Synapse 1, 133-152. doi: 10.1002/syn.890010203

Shifman, S., Bronstein, M., Sternfeld, M., Pisante-Shalom, A., Lev-Lehman, E., Weizman, A., et al. (2002). A highly significant association between a COMT haplotype and schizophrenia. Am. J. Hum. Genet. 71, 1296-1302. doi: $10.1086 / 344514$

Shively, C. A., Register, T. C., Higley, J. D., and Willard, S. L. (2014). Sertraline effects on cerebrospinal fluid monoamines and species-typical socioemotional behavior of female cynomolgus monkeys. Psychopharmacology (Berl) 231, 1409-1416. doi: 10.1007/s00213-013-3329-9

Stevens, A., and Price, J. (2000). Evolutionary Psychiatry: A New Beginning. London, UK: Routledge.
Suhara, T., Yasuno, F., Sudo, Y., Yamamoto, M., Inoue, M., Okubo, Y., et al. (2001). Dopamine D2 receptors in the insular cortex and the personality trait of novelty seeking. Neuroimage 13, 891-895. doi: 10.1006/nimg.2001.0761

Sullivan, P. F., Daly, M. J., and O'donovan, M. (2012). Genetic architectures of psychiatric disorders: the emerging picture and its implications. Nat. Rev. Genet. 13, 537-551. doi: 10.1038/nrg3240

Svensson, E., Woolley, J., Wikstrom, M., and Grillner, S. (2003). Endogenous dopaminergic modulation of the lamprey spinal locomotor network. Brain Res. 970, 1-8. doi: 10.1016/S0006-8993(02)04216-6

Thompson, J., Thomas, N., Singleton, A., Piggott, M., Lloyd, S., Perry, E. K., et al. (1997). D2 dopamine receptor gene (DRD2) Taq1 A polymorphism: reduced dopamine D2 receptor binding in the human striatum associated with the A1 allele. Pharmacogenetics 7, 479-484. doi: 10.1097/00008571-199712000-00006

Torrey, E. F. (1987). Prevalence studies in schizophrenia. Br. J. Psychiatry 150, 598-608. doi: 10.1192/bjp.150.5.598

Tournier, B. B., Steimer, T., Millet, P., Moulin-Sallanon, M., Vallet, P., Ibanez, $\mathrm{V}$., et al. (2013). Innately low D2 receptor availability is associated with high novelty-seeking and enhanced behavioural sensitization to amphetamine. Int. J. Neuropsychopharmacol. 16, 1819-1834. doi: 10.1017/S1461145713 000205

Vanderschuren, L. J., and Kalivas, P. W. (2000). Alterations in dopaminergic and glutamatergic transmission in the induction and expression of behavioral sensitization: a critical review of preclinical studies. Psychopharmacology (Berl) 151, 99-120. doi: 10.1007/s002130000493

Veltman, J. A., and Brunner, H. G. (2012). De novo mutations in human genetic disease. Nat. Rev. Genet. 13, 565-575. doi: 10.1038/nrg3241

Visser, S. N., Bitsko, R. H., Danielson, M. L., Perou, R., and Blumberg, S. J. (2010). Increasing prevalence of parent-reported attention-deifict/hyperactivity disorder among children - United States, 2003 and 2007. Morb. Mortal. Wkly. Rep. 59, 1439-1443.

Von Huben, S. N., Davis, S. A., Lay, C. C., Katner, S. N., Crean, R. D., and Taffe, M. A. (2006). Differential contributions of dopaminergic D1- and D2-like receptors to cognitive function in rhesus monkeys. Psychopharmacology (Berl) 188, 586-596. doi: 10.1007/s00213-006-0347-x

Walters, K. L., Simoni, J. M., and Evans-Campbell, T. (2002). Substance use among American Indians and Alaska natives: incorporating culture in an "indigenist" stress-coping paradigm. Public Health Rep. 117(Suppl. 1), S104-S117.

Weaver, I. C., Cervoni, N., Champagne, F. A., D’alessio, A. C., Sharma, S., Seckl, J. R., et al. (2004). Epigenetic programming by maternal behavior. Nat. Neurosci. 7, 847-854. doi: $10.1038 / \mathrm{nn} 1276$

Welsh, J. H. (1972). "Catecholamines in the invertebrates," in Catecholamines, eds H. Blaschko and E. Muscholl (Berlin Heidelberg: Springer), 79-109.

Willuhn, I., Tose, A., Wanat, M. J., Hart, A. S., Hollon, N. G., Phillips, P. E., et al. (2014). Phasic dopamine release in the nucleus accumbens in response to prosocial $50 \mathrm{kHz}$ ultrasonic vocalizations in rats. J. Neurosci. 34, 10616-10623. doi: 10.1523/JNEUROSCI.1060-14.2014

Zahrt, J., Taylor, J. R., Mathew, R. G., and Arnsten, A. F. (1997). Supranormal stimulation of D1 dopamine receptors in the rodent prefrontal cortex impairs spatial working memory performance. J. Neurosci. 17, 8528-8535.

Zald, D. H., Cowan, R. L., Riccardi, P., Baldwin, R. M., Ansari, M. S., Li, R., et al. (2008). Midbrain dopamine receptor availability is inversely associated with novelty-seeking traits in humans. J. Neurosci. 28, 14372-14378. doi: 10.1523/JNEUROSCI.2423-08.2008

Zou, Y. F., Wang, F., Feng, X. L., Li, W. F., Tian, Y. H., Tao, J. H., et al. (2012). Association of DRD2 gene polymorphisms with mood disorders: a meta-analysis. J. Affect. Disord. 136, 229-237. doi: 10.1016/j.jad.2010.11.012

Conflict of Interest Statement: The authors declare that the research was conducted in the absence of any commercial or financial relationships that could be construed as a potential conflict of interest.

Copyright $(2015$ Yamaguchi, Lee and Goto. This is an open-access article distributed under the terms of the Creative Commons Attribution License (CC BY). The use, distribution or reproduction in other forums is permitted, provided the original author(s) or licensor are credited and that the original publication in this journal is cited, in accordance with accepted academic practice. No use, distribution or reproduction is permitted which does not comply with these terms. 